\title{
Evaluation of trypanocidal drugs used for human African trypanosomosis against Trypanosoma lewisi
}

\author{
Mariette Dethoua ${ }^{1, a}$, Romaric Nzoumbou-Boko ${ }^{1, a}$, Philippe Truc ${ }^{2}$, Sylvie Daulouède ${ }^{1}$, Pierrette Courtois ${ }^{1}$, \\ Bruno Bucheton ${ }^{2}$, Gérard Cuny ${ }^{2}$, Silla Semballa ${ }^{1}$, and Philippe Vincendeau ${ }^{1}{ }^{*}$ \\ 1 Laboratoire de Parasitologie, BP 43, UMR 177 IRD CIRAD Université de Bordeaux, 33076 Bordeaux Cedex, France \\ 2 Institut de Recherche pour le Développement, Unité Mixte de Recherche 177 IRD-CIRAD, Campus International de Baillarguet, \\ TA A17/G, 34398 Montpellier Cedex 5, France
}

Received 13 September 2013, Accepted 6 October 2013, Published online 22 October 2013

\begin{abstract}
Trypanosomes from animals are potential pathogens for humans. Several human cases infected by Trypanosoma lewisi, a parasite of rats, have been reported. The number of these infections is possibly underestimated. Some infections were self-cured, others required treatment with drugs used in human African trypanosomosis. An in vitro evaluation of these drugs and fexinidazole, a new oral drug candidate, has been performed against $T$. lewisi in comparison with T. brucei gambiense. All have comparable activities against the two parasites. Suramin was not effective. In vivo, drugs were tested in rats immunosuppressed by cyclophosphamide. The best efficacy was obtained for fexinidazole, and pentamidine $(15 \mathrm{mg} / \mathrm{kg})$ : rats were cured in 7 and 10 days respectively. Rats receiving nifurtimoxeflornithine combination therapy (NECT) or pentamidine $(4 \mathrm{mg} / \mathrm{kg})$ were cured after 28 days, while melarsoprol was weakly active. The identification of efficient drugs with reduced toxicity will help in the management of new cases of atypical trypanosomosis
\end{abstract}

Key words: Trypanosome, Trypanosoma lewisi, Trypanocidal drugs, Fexinidazole, Atypical trypanosomiasis.

\begin{abstract}
Résumé - Évaluation des médicaments trypanocides utilisés dans la trypanosomose humaine africaine contre Trypanosoma lewisi. Les trypanosomes d'animaux sont potentiellement pathogènes pour l'homme. Plusieurs infections humaines par Trypanosoma lewisi, parasite du rat, ont été rapportées. Leur nombre est probablement sous-estimé. Certaines de ces infections auto-guérissent, d'autres nécessitent un traitement avec des médicaments utilisés dans la trypanosomose humaine africaine. Une évaluation in vitro de ces médicaments et du fexinidazole, un nouveau candidat-médicament actif par voie orale, a été réalisé sur $T$. lewisi en comparaison avec $T$. brucei gambiense. Tous ont présenté des effets comparables contre les deux parasites sauf la suramine qui n'était pas efficace. In vivo, ces médicaments ont été administrés à des rats immunodéprimés par le cyclophosphamide. La meilleure efficacité a été obtenue avec le fexinidazole et la pentamidine $(15 \mathrm{mg} / \mathrm{kg})$ : les rats ont été guéris en respectivement 7 et 10 jours. Ceux recevant la combinaison thérapeutique nifurtimox-éflornithine (NECT) ou pentamidine $(4 \mathrm{mg} / \mathrm{kg})$ ont été guéris au bout de 28 jours, tandis que le mélarsoprol était faiblement actif. L'identification de médicaments efficaces peu toxiques aidera à la prise en charge de nouveaux cas de trypanosomose atypique.
\end{abstract}

\section{Introduction}

Trypanosoma (Herpetosoma) lewisi is an extracellular protozoan blood parasite of rats and is distributed worldwide [8]. It is naturally transmitted to rats by fleas. T. lewisi has a limited antigenic variation $[6,15]$. In rats, $T$. lewisi infection is self-limited leading to elimination of circulating parasites and protection against re-infection. The typical pathogenic human

\footnotetext{
a Mariette Dethoua and Romaric Nzoumbou-Boko contributed equally to this article

* Corresponding author:

philippe.vincendeau@u-bordeaux2.fr
}

trypanosomes are $T$. brucei gambiense, $T$. $b$. rhodesiense and T. cruzi [8]. Humans possess an innate protection against most trypanosomes species from animals [21]. However, trypanosomes from animals can in some cases be pathogens for humans. For instance, in 1933, a case of febrile Malaysian child presenting numerous $T$. lewisi parasites was reported [13]. In India, T. lewisi were detected in two adults [18] leading to self-cured while a baby was treated using pentamidine in 2010 [23]. These atypical human infections by animal trypanosomes were recently reviewed [20]. However, no evaluation of trypanocidal drugs, including the combination nifurtimox/eflornithine NECT [17], has been performed against $T$. lewisi. In this

This is an Open Access article distributed under the terms of the Creative Commons Attribution License (http://creativecommons.org/licenses/by/2.0), which permits unrestricted use, distribution, and reproduction in any medium, provided the original work is properly cited. 
study, the efficacy of these drugs against $T$. lewisi was investigated in vitro and in vivo in cyclophosphamide (CPA)-treated and T. lewisi-infected rats [5]. The efficacy of Fexinidazole, a new oral nitroimidazole drug candidate for treatment of both stages in human African trypanosomosis (HAT), was also evaluated [19].

\section{Materials and methods}

\section{Animals and ethics}

Female Swiss mice, 18-20 g, and Wistar rats, 90-100 g (Charles River, L'Arbresle, France) were kept in our animal housing facility for more than a week before the experiment was started. Experiments on animals complied with guidelines of the European Convention for the Protection of Vertebrate Animals used for Experimental and other Scientific Purposes (CETS No. 123). Experiments were approved by the Department for the protection of animals and plants of the Préfecture de la Gironde (January 2012) including experiments on drug activity and toxicity (Identification number A33-063-324).

\section{Parasites}

T. b. gambiense (Feo/ITMAP/1893) was used for in vitro experiment. Swiss mice were infected by intraperitoneal injection (IP) with $10^{4}$ parasites diluted in physiological saline.

T. lewisi (Wery L307 24/9/68), kindly provided by Étienne Pays and Pierrick Uzureau (Université Libre de Bruxelles, Gossselies, Belgium), was used for in vitro and in vivo experiments. Rats were infected by IP injection of $5 \times 10^{4}$ parasites diluted in physiological saline.

Parasites were purified from rodent blood using DEAEcellulose.

\section{Drugs}

Current drugs used in HAT (pentamidine, suramin, melarsoprol, eflornithine, nifurtimox) were kindly supplied by World Health Organization. Fexinidazole was kindly supplied by Sanofi.

\section{In vitro assessment of drugs}

Each well of a 96-well plate (Falcon Plastics, Oxnard, CA, USA) was filled with $100 \mu \mathrm{L}$ of culture medium McCoy 5A modified medium supplemented with $100 \mathrm{U} / \mathrm{mL}$ penicillin, $100 \mu \mathrm{g} / \mathrm{mL}$ streptomycin, $25 \mathrm{mM}$ HEPES, $0.1 \mathrm{mM}$ 2-mercaptoethanol, $2 \mathrm{mM}$ sodium pyruvate, $0.2 \mathrm{mM} L$-cysteine and $10 \%$ foetal calf serum $[1,24]$. Nifurtimox and fexinidazole were first dissolved in $100 \%$ dimethyl sulphoxide (DMSO). Adequate dilutions in culture medium of each compound were added into each well in triplicate while control wells contained medium alone or with DMSO (0.4\%). Then $100 \mu \mathrm{L}$ of a suspension containing $10^{5}$ blood-purified parasites was added in each well. Cultures were maintained at $37{ }^{\circ} \mathrm{C}$ in $5 \% \mathrm{CO}_{2}$ incubator for $24 \mathrm{~h}$. Parasite count was performed using a haemocytometer. The activity was expressed in concentration inhibiting parasite growth by $50 \%\left(\mathrm{IC}_{50}\right)$ [16]. All experiments were performed twice, with each drug concentration in triplicate. The mean of IC50 and standard deviation $(S D)$ obtained for the six cultures of each drug were calculated.

\section{In vivo assessment}

Female rats were immunosuppressed by IP injection of CPA $(100 \mathrm{mg} / \mathrm{kg}) 72 \mathrm{~h}$ before infection by IP injection of $5 \times 10^{4}$ purified $T$. lewisi diluted in physiological saline.

On day 7 after infection, parasitemias were evaluated in blood collected by tail cutting [9]. Parasite counting was carried out using an haemocytometer for each rat, and six groups of seven rats were then randomly distributed:

- One group received pentamidine $(4 \mathrm{mg} / \mathrm{kg})$ by IP injection for 28 days;

- One group received pentamidine $(15 \mathrm{mg} / \mathrm{kg})$ by IP injection for 12 days;

- One group received three cures of melarsoprol $(3.6 \mathrm{mg} / \mathrm{kg} /$ day) by IP injection, each cure is composed of 3 days spaced by a 7 day resting period;

- One group received fexinidazole $(100 \mathrm{mg} / \mathrm{kg})$ orally for 10 days;

- One group received eflornithine (200 mg/kg, twice a day) by IP injection and nifurtimox $(10 \mathrm{mg} / \mathrm{kg}$, twice a day) orally for 28 days;

- One group (control group) received physiological saline $(0.5 \mathrm{~mL} /$ day $)$ by IP injection for 28 days.

The number of parasites observed for each group was estimated as the mean of daily parasitaemia of the seven rodents.

\section{Statistical analysis}

Parasitaemias are represented as the mean of the group $\pm S D$. The comparisons between groups were made using the non-parametric Wilcoxon/Kruskal-Wallis test implemented in the JMP7 software.

\section{Results}

\section{In vitro activity of drugs against trypanosomes}

The reference drugs, pentamidine, suramin, melarsoprol, eflornithine and fexinidazole, were assessed for in vitro efficacy against trypanosomes. Their activity against T. lewisi and T. $b$. gambiense was compared. Pentamidine, eflornithine, nifurtimox and fexinidazole have comparable activities against the two parasites while melarsoprol is less active against $T$. lewisi than T. $b$. gambiense (Table 1). Suramin was not effective against the two parasites, and, due to its toxicity [22], suramin was not investigated further. The highest concentration of DMSO $(0.4 \%$ in culture medium) had no trypanocidal activity.

\section{In vivo assessment of drugs}

In rats infected by $T$. lewisi but not immunosuppressed by CPA, the blood parasite number was too low to allow a comparison between drugs (data not shown). 
Table 1. In vitro activities of trypanocidal drugs $\left(\mathrm{IC}_{50}(\mu \mathrm{M})\right)$.

\begin{tabular}{lll}
\hline & T. lewisi & T. b. gambiense \\
\hline Melarsoprol & $0.09 \pm 0.01$ & $0.03 \pm 0.01$ \\
Pentamidine & $0.07 \pm 0.02$ & $0.06 \pm 0.02$ \\
Eflornithine & $20.5 \pm 8.7$ & $25.1 \pm 12.4$ \\
Nifurtimox & $4.25 \pm 1.06$ & $3.12 \pm 1.27$ \\
Fexinidazole & $3.75 \pm 0.85$ & $2.55 \pm 0.42$ \\
\hline
\end{tabular}

Each result is the mean $\pm S D$ of $\mathrm{IC}_{50}$ for six cultures.

For rats which received CPA $(100 \mathrm{mg} / \mathrm{kg}) 3$ days before infection, drugs were given orally or by IP injection starting at day 7 after infection when parasite blood count was about $1.5 \times 10^{7} / \mathrm{mL}$.

No animal died. In the control group (animals injected with physiological saline), a steady decrease of blood parasitaemia was observed after day 10. Nevertheless some animals remained infected over the all experimental period and still displayed parasitaemia levels $\left(>10 \times 10^{6}\right.$ parasites $\left./ \mathrm{mL}\right) 43$ days after infection. As compared to controls, the control of parasitaemia was quicker for the animals of the fexinidazole and pentamidine $(15 \mathrm{mg} / \mathrm{kg})$ groups with all animals being cured respectively 7 and 10 days after treatment. The decay rate of blood parasitaemia was slower in the NECT and pentamidine $(4 \mathrm{mg} / \mathrm{kg}$ ) groups and all animals were cured after 33 and 35 days post infection respectively. Mean parasitaemia (parasites/ $\mathrm{mL})$ was however significantly lower $(p=0.006)$ in the NECT group $\left(9 \times 10^{6}\right.$; calculated from day 7 to day 32 post infection $)$ than in the pentamidine $(4 \mathrm{mg} / \mathrm{kg})$ group $\left(15.8 \times 10^{6}\right.$; calculated from day 7 to day 34 post infection). The evolution of parasitaemia in the melarsoprol group was not significantly different from the controls until day 33 post infection and animals were finally cured at day 42 post infection although three animals of this group died during the experiment whereas no animal from others groups died. For each group, the sum of daily parasitaemia means (considered as whole parasite load and corresponding to area under the curves in Figure 1) $\pm S D$ was assessed from day 6 to day 43 post infection. The values were $724.36 \pm 53$ for control group, $103.76 \pm 9.2$ for fexinidazole group, $167.264 \pm 11.1$ for pentamidine $(15 \mathrm{mg} / \mathrm{kg})$ group, $252.318 \pm 22.1$ for NECT group, and $412.578 \pm 28$ for pentamidine ( $4 \mathrm{mg} / \mathrm{kg}$ ) group. Compared to control group, parasite load was lower in all treated groups $(p<0.001)$. Compared to pentamidine $(15 \mathrm{mg} / \mathrm{kg})$ group, parasite load was lower in fexinidazole group $(p<0.05)$.

All treated rats remained negative in parasitology until 90 days post infection.

\section{Discussion}

In this study, the efficacy of drugs for HAT treatment and fexinidazole against $T$. lewisi was demonstrated both in vitro and in vivo.

Melarsoprol and pentamidine have already been used successfully in two T. lewisi human infections [11, 23]. In vitro studies reveal a comparable susceptibility profile of $T$. lewisi and T. $b$. gambiense. Fexinidazole was both efficient against T. lewisi and T. b. gambiense. A single strain of T. lewisi was tested and other ones from various sources will be analysed very soon. However, fexinidazole possesses an in vitro trypanocidal efficiency on all tested brucei subspecies, in the range of $0.7-3.3 \mu \mathrm{M}$ and is also efficient on other parasites [2-30].

Rats were immunosuppressed using CPA at non-lethal doses to increase parasitemias [5]. In spite of heavy parasitaemia developed in CPA-treated rats, the brain remained free of parasites [5]. CPA mediates immunosuppression, which might mimic a potential but not established immunodeficiency in atypical human infections by animal trypanosomes. Some trypanocidal drugs require an intact immune system for clearance of trypanosomes [4] whereas nitroimidazoles are active compounds against various infectious agents, largely used and efficient in immunocompromised patients [10]. Fexinidazole and NECT were active at the doses recommended for HAT treatment but cure was obtained earlier with fexinidazole. However, fexinidazole may be active at lower doses and a further study will determine its minimum effective dose. Pentamidine was not active at the dose of $4 \mathrm{mg} / \mathrm{kg}$, which is recommended in humans for African trypanosomiasis and Pneumocystis jirovecii pneumonia treatment. As superior doses exhibit activity in Pneumocystis jirovecii-infected rats [29], a $15 \mathrm{mg} / \mathrm{kg}$ dose was also assessed in T. lewisi-infected rats and was efficient.

Whereas human infections with T. lewisi can self-cure, it is not always the case [20]. Thus evaluating the efficacy of available drugs is of interest, in particular when T. lewisi are present in cerebrospinal fluid, as reported previously [11]. Fexinidazole and NECT are both efficient for patients in the neurological stage of HAT [19]. Compared to melarsoprol and eflornithine, NECT has a reduced toxicity and is much easier to administer [17]. Animal toxicology studies reveal that fexinidazole has an excellent safety profile [19]. A reduced toxicity of the drug, a better control of parasite number and persistence, a reduced production of TNF- $\alpha$ and reactive oxygen species by activated macrophages [25] might be beneficial in treatment by fexinidazole.

The number of atypical human infections attributable to primarily animal trypanosomes is possibly underestimated, mainly due to lack of tools and strategies to better detect infection [20]. Interaction with others factors might be involved in atypical human infections by animal trypanosomes. For instance, diet deficiency enhanced T. lewisi infections in rats, as also reported for the related murine parasite, T. musculi [12]. Moreover, immunomodulation of immune response might also be involved. The binding of immunoglobulins by parasites via receptors for their Fc region might cover parasites and decrease the efficiency of host immune response $[3,30]$. The risk and potential impact related to atypical human infections by animal trypanosomes cannot be evaluated thoroughly at the present time and further studies are required. However the identification of drugs efficient against T. lewisi with reduced toxicity will help in the management of new cases. Fexinidazole and pentamidine $(15 \mathrm{mg} / \mathrm{kg})$ represent valuable drugs to treat $T$. lewisi infections.

Acknowledgements. We thank Dr. Jean Jannin and Dr. Péré Perez Simarro (World Health Organization) for the supply of pentamidine, suramin, melarsoprol, eflornithine, nifurtimox and Dr. Olivier Petigny (Sanofi) for the supply of fexinidazole. The technical assistance by Patricia Nabos was greatly appreciated. We thank le Service de coopération et d'action culturelle de l'Ambassade de France a 


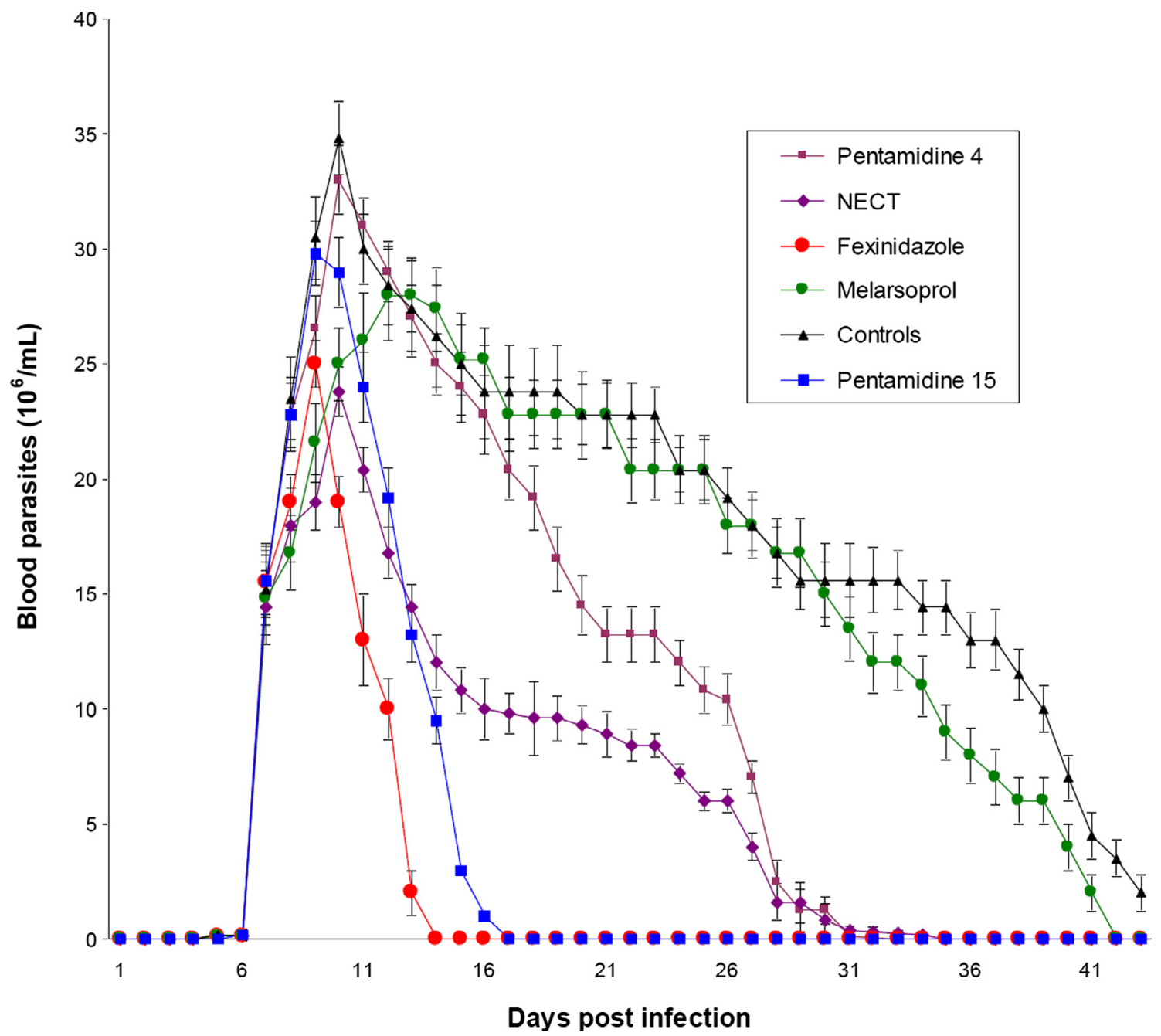

Figure 1. Evolution of parasitemias for $T$. lewisi-infected rats during 43 days after infection. Rats were infected by IP injection of $5 \times 10^{4}$ purified T. lewisi and randomly divided in six groups at day 7 post infection. Each group received drugs as described. Parasitemias were monitored every day.

Bangui, le conseil régional d'Aquitaine and l'Association pour le développement de la recherche en parasitologie et santé tropicale for continuous support.

\section{References}

1. Albright JW, Albright JF. 1980. In vitro growth of Trypanosoma musculi in cell-free medium conditioned by rodent macrophages and mercaptoethanol. International Journal of Parasitology, 10, 137-142.

2. Bahia MT, de Andrade IM, Martins TA, do Nascimento ÁF, Diniz Lde F, Caldas IS, Talvani A, Trunz BB, Torreele E, Ribeiro I. 2012. Fexinidazole: a potential new drug candidate for Chagas disease. PLoS Neglected Tropical Diseases, 6, e1870. Doi: 10.1371/journal.pntd.0001870

3. Balber AE, Sturtevant JE. 1986. A surface glycoprotein of Trypanosoma lewisi binds immunoglobulin $\mathrm{G}$ from the serum of uninfected rats. Infection and Immunity, 53, 420-426.

4. Berger BJ, Fairlamb AH. 1992. Interactions between immunity and chemotherapy in the treatment of the trypanosomiases and leishmaniases. Parasitology, 105, S71-S78.
5. Budovsky A, Prinsloo I, El-On J. 2006. Pathological developments mediated by cyclophosphamide in rats infected with Trypanosoma lewisi. Parasitology International, 55, 237-242.

6. D'Alessandro PA, Behr MA. 1991. Trypanosoma lewisi and its relatives. In Krerer J, Baker JR (Eds.), Parasitic protozoa. Academic Press, New York, pp. 225-263.

7. Hirumi H, Hirumi K. 1989. Continuous cultivation of Trypanosoma brucei blood stream forms in a medium containing a low concentration of serum protein without feeder cell layers. Journal of Parasitology, 75, 985-989.

8. Hoare CA. 1972. The Trypanosomes of Mammals. A Zoological Monograph. Blackwell Scientific Publications: Oxford and Edinburgh. p. 1-749.

9. Holzmuller P, Dg Biron, Courtois P, Koffi M, Bras-Gonçalves R, Daulouède S, Solano P, Cuny G, Vincendeau P, Jamonneau V. 2008. Virulence and pathogenicity patterns of Trypanosoma brucei gambiense field isolates in experimentally infected mouse: differences in host immune response modulation by secretome and proteomics. Microbes and Infections, 10, 79-86.

10. Hosseini pour MC, Napravnik S, Joaki G, Gama S, Mbeye N, Banda B, Martinson F, Hoffman I, Cohen MS. 2007. HIV and parasitic infection and the effect of treatment among adult 
outpatients in Malawi. Journal of Infectious Diseases, 195, $1278-1282$.

11. Howie S, Guy M, Fleming L, Bailey W, Noyes H. 2006. A Gambian infant with fever and an unexpected blood film. PLoS Medicine, 3, 1508-1512.

12. Humphrey PA, Ashraf M, Lee CM. 1997. Growth of trypanosomes in vivo, host body weight gains, and food consumption in zinc-deficient mice. Journal of the National Medical Association, 89, 48-56.

13. Johnson PD. 1933. A case of infection by Trypanosoma lewisi in a child. Transaction of the Royal Society Tropical Medicine and Hygiene, 26, 467-468.

14. Kaiser M, Bray MA, Cal M, Bourdin Trunz B, Torreele E, Brun R. 2011. Antitrypanosomal activity of fexinidazole, a new oral nitroimidazole drug candidate for treatment of sleeping sickness. Antimicrobial Agents Chemotherapy, 55, 5602-5608.

15. Molyneux D. 1976. Biology of the trypanosomes of the subgenus Herpetosoma, in Biology of the Kinetoplastida. Lumsden WHR, Evans DA (Eds.), Academic Press: London. pp. 285-325.

16. Pomel S, Biot C, Bories C, Loiseau PM. 2013. Antiprotozoal activity of ferroquine. Parasitology Research, 112, 665-669.

17. Priotto G, Kasparian S, Mutombo W, Ngouama D, Ghorashian S, Arnold U, Ghabri S, Baudin E, Buard V, Kazadi-Kyanza S, Ilunga M, Mutangala W, Pohlig G, Schmid C, Karunakara U, Torreele E, Kande V. 2009. Nifurtimox-eflornithine combination therapy for second-stage African Trypanosoma brucei gambiense trypanosomiasis: a multicentre, randomised, phase III, non-inferiority trial. Lancet, 374, 56-64.

18. Shrivastava KK, Shrivastava GP. 1974. Two cases of Trypanosoma (Herpetosoma) species infection of man in India. Transaction of the Royal Society Tropical Medicine and Hygiene, 68, 143-144.

19. Torreele E, Bourdin Trunz B, Tweats D, Kaiser M, Brun R, Fexinidazole. 2010. A new oral nitroimidazole drug candidate entering clinical development for the treatment of sleeping sickness. PLoS Neglected Tropical Diseases, 4(12), e923. Doi: 10.1371/journal.pntd.0000923

20. Truc P, Büscher P, Cuny G, Mi Gonzatti, Jannin J, Prashant J, Prayag J, Zhao-Rong L, Mattioli R, Pays E, Simarro PP, Geraldes-Teixeira MM, Touratier L, Vincendeau P, Desquesnes M. 2013. Atypical human infections by animal trypanosomes.
PLoS Neglected Tropical Diseases, 7(9), e2256,

Doi: 10.1371/journal.pntd.0002256

21. Vanhamme L, Paturiaux-Hanocq F, Poelvoorde P, Nolan DP, Lins L, Van Den Abbeele J, Pays A, Tebabi P, Van-Xong H, Jacquet A, Moguilevsky N, Dieu M, Kane J, De Baetselier P, Brasseur R, Pays E. 2003. Apolipoprotein L-I is the trypanosome lytic factor of human serum. Nature, 422, 83-87.

22. Van Voorhis WC. 1990. Therapy and prophylaxis of systemic protozoan infections. Drugs, 40, 176-202.

23. Verma A, Manchanda S, Kumar N, Sharma A, Goel M. 2011. Trypanosoma lewisi or T. lewisi-like infection in a 37 day old infant. American Journal of Tropical Medicinal and Hygiene, 85, 221-224.

24. Vincendeau P, Daulouède S, Veyret B, Darde ML, Bouteille B, Lemesre JL. 1992. Nitric oxide-mediated cytostatic activity on Trypanosoma brucei gambiense and Trypanosoma brucei brucei. Experimental Parasitology, 75, 353-360.

25. Vincendeau P, Caristan A, Pautrizel R. 1981. Macrophage functions during Trypanosoma musculi infection in mice. Infections and Immunity, 34, 78-81.

26. Vincendeau P, Daeron M. 1989. Trypanosoma musculi coexpress several receptors binding rodent $\operatorname{IgM}, \operatorname{IgE}$, and $\operatorname{IgG}$ subclasses. Journal of Immunology, 142, 1702.

27. Vincendeau P, Guillemain B, Daulouede S, Ripert C. 1986. In vitro growth of Trypanosoma musculi requirements of cells and serum-free culture medium. International Journal of Parasitology, 16, 387-390.

28. Vincendeau P, Daeron M, Daulouede S. 1986. Identification of antibody classes and $\mathrm{Fc}$ receptors responsible for phagocytosis of Trypanosoma musculi by mouse macrophages. Infection and Immunity, 53, 600-606.

29. Walzer PD, Kim CK, Foy J, Linke MJ, Cushion MT. 1988. Cationic antitrypanosomal and other antimicrobial agents in the therapy of experimental Pneumocystis carinii pneumonia. Antimicrobial Agents and Chemotherapy, 32, 896-905.

30. Wyllie S, Patterson S, Stojanovski L, Simeons FR, Norval S, Kime R, Read KD, Fairlamb AH. 2012. The anti-trypanosome drug fexinidazole shows potential for treating visceral leishmaniasis. Science Translational Medicine, 4, 119. Doi: 10.1126/scitranslmed.3003326

Cite this article as: Dethoua M, Nzoumbou-Boko R, Truc P, Daulouède S, Courtois P, Bucheton B, Cuny G, Semballa S \& Vincendeau P: Evaluation of trypanocidal drugs used for human African trypanosomosis against Trypanosoma lewisi. Parasite, 2013, 20, 39 .

Reviews, articles and short notes may be submitted. Fields include, but are not limited to: general, medical and veterinary parasitology; morphology, including ultrastructure; parasite systematics, including entomology, acarology, helminthology and protistology, and molecular analyses; molecular biology and biochemistry; immunology of parasitic diseases; host-parasite relationships; ecology and life history of parasites; epidemiology; therapeutics; new diagnostic tools.

All papers in Parasite are published in English. Manuscripts should have a broad interest and must not have been published or submitted elsewhere. No limit is imposed on the length of manuscripts.

Parasite (open-access) continues Parasite (print and online editions, 1994-2012) and Annales de Parasitologie Humaine et Comparée (1923-1993) and is the official journal of the Société Française de Parasitologie. 